Indian J. Anim. HIth. (2018), 57(2) : 243-245

Short Communication

\title{
CERVICO-VAGINAL PROLAPSE AND ITS MANAGEMENT: A CASE REPORT
}

\author{
V. VAID, T. GUPTA ${ }^{1}$, K. MAHAJAN \\ S. F. AHMAD ${ }^{1 * A N D ~ A . ~ S I N G H ~}$ \\ Faculty of Veterinary Sciences and Animal Husbandry \\ Sher-e-Kashmir University of Agricultural Sciences and Technology-Jammu \\ Jammu and Kashmir, India-180 009
}

\begin{abstract}
Four years old cattle in its first month of pregnancy was presented with complaint of a mass hanging from the genital opening. Its recurrence was reported by the owner. General examination of the animal was carried out and the temperature was recorded as $99.8^{\circ} \mathrm{F}$. The animal exhibited the signs of restlessness and the protruding mass was edematous and swollen. The physical examination confirmed cervicovaginal prolapse. The perineal region of the cow was prepared for aseptic surgery. The animal was operated under epidural anesthesia using $2 \%$ lignocaine hydrochloride $(10 \mathrm{~mL})$. The prolapsed mass was cleaned with dilute $(1 \%)$ potassium permanganate solution and the mass was lifted with both hands and replaced into the vagina by using fist support. Afterwards, $2 \%$ lignocaine hydrochloride was administered subcutaneously into the lips of the vagina where the Gerlach needle was punctured. Buhner's suture was applied with rope parallel to the vulva keeping one hand space for easy urination. Sutures were removed after 1 month of the surgical intervention. The owner was advised for proper post-operative care for preventing its recurrence. The cow was followed for the next 2 months. It recovered successfully without any further complications.
\end{abstract}

Key words: Buhner's suture, Cervico-vaginal prolapse, Gerlach needle, Tenesmus

Cervico-vaginal (CV) prolapse is one of the most commonly observed conditions in cows, buffaloes and sheep (Patra et al., 2014). The incidence of prolapse has been well elaborated in cows (Arthur et al., 1989; Roberts, 1971). With hereditary basis, the disorder is chronic and recurrent in nature. Vaginal prolapse typically occurs before calving usually in the heavily pregnant cow, particularly during the last quarter of gestation. The exact etiology of $\mathrm{CV}$ prolapse is unknown but the factors that

* Corresponding Author

${ }^{1}$ ICAR-Indian Veterinary Research Institute, Izatnagar, Bareilly, UP- 243 122, India 
predispose towards genital prolapse are increased intra-abdominal pressure, obesity and prolonged tenesmus (Jena et al., 2013). Henricks et al. (2011) reported higher incidence of prolapse cases with increased estrogens and decreased progesterone levels, especially in the last two weeks of pregnancy. Feed containing estrogenic substances, such as clover pasture, soybean meal, moldy maize and barley are reported to increase the incidence of genital prolapse in animals (Bhattacharyya et al., 2012). Vaginal prolapse is considered an emergency condition that demands immediate intervention, otherwise threats of trauma, laceration, hemorrhage and bacterial infection are inevitable (Hasan et al., 2017). Sometimes, the prolapse may cause infertility in subsequent pregnancies. After proper reduction of the edematous, swollen prolapsed mass, various suturing techniques have been tried but they are prone to tear the vulva, particularly in cases that show violent straining after suturing. Buhner's subcutaneous peri-vulvar suture application is recommended along with the use of vetafil or umbilical tape (Bhattacharyya et al., 2012).

Four years old cow in its first month of pregnancy was presented with complaint of a mass hanging from the genital opening. The cow was restless with pain and temperature was $99.8^{\circ} \mathrm{F}$. The examination of the hanging mass revealed it to be cervico-vaginal prolapsed mass. The mass was red, swollen and edematous as shown in Fig. $1 \& 2$.
The cow was first anesthetized with $2 \%$ lignocaine hydrochloride $(10 \mathrm{~mL})$ at first inter-coccygeal space. The prolapsed mass was then carefully washed with a dilute (1\%) potassium permanganate solution to remove dirt. The prolapsed mass was lifted and replaced by to its original position in the vagina by using fist support. Then with Gerlach needle puncture in vaginal lips, $2 \%$ lignocaine hydrochloride was administered. Buhner's suture was applied with rope parallel to the vulva apart from the vagina keeping one hand space for easy urination. The animal was then injected with vitamin B complex (Tribivet- $10 \mathrm{~mL}$ ) and calcium supplement (Mifex-450 mL) and Meloxicam $(5 \mathrm{~mL})$. For post-operative treatment, $5 \%$ dextrose normal saline (DNS) was administered for 3 days, calcium supplement $(10 \mathrm{~mL})$ for 3 days and povidone iodine ointment was recommended for application on vulvar lips. The owner was advised to take proper post-operative care for preventing its recurrence. Sutures were removed after 1 month. The cow was followed postoperatively for the period of 2 months.

Vaginal prolapse is one of the recurrent, chronic conditions which can cause economic losses to farmers. It can hamper the milk production of cows. It mainly appears at last trimester of gestation in pluriparous cows as compared to heifers (Noakes et al., 2009). Immediate treatment is important before the condition worsens as this condition places high stress on animals. In delayed cases, fatal septicemia may develop (Bhattacharyya et al., 2007). 
Indian Journal of Animal Health, December, 2018

Management of cervico-vaginal prolapse

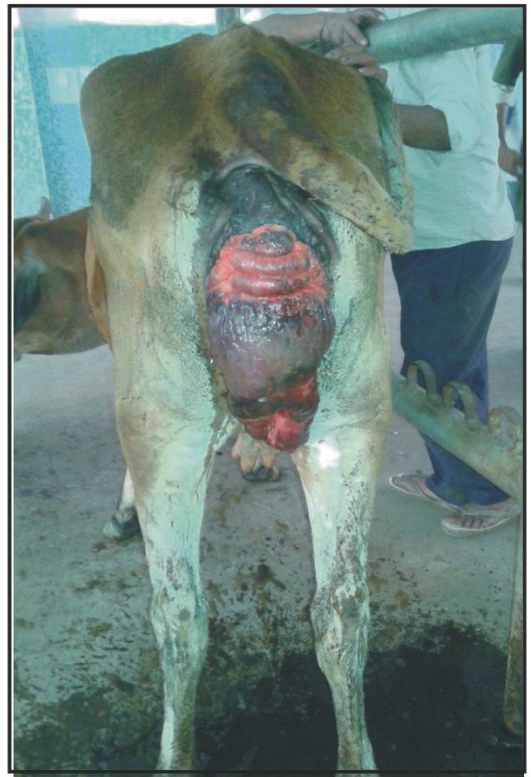

Fig. 1. Cow with a prolapsed vagina in a standing condition

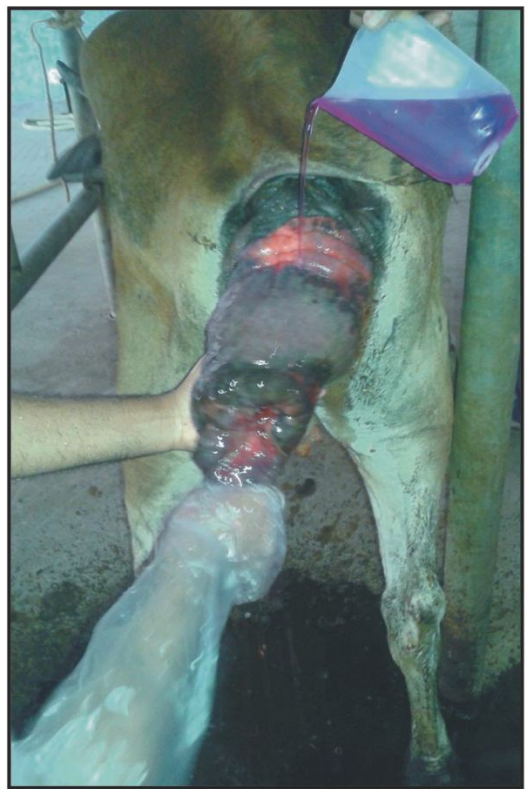

Fig. 2. Washing of prolapsed mass with dilute potassium permanganate 
The exact etiology is not known. Buhner method of suturing is efficient and suitable for large animals.

Conflict of interest: The authors declare no conflict of interest for this manuscript.

\section{REFERENCES}

Arthur GH, Noakes DE and Pearson H, 1989. Veterinary Reproduction and Obstetrics. (Theriogenology). 6th Edn., ELBS., Bailliere Tindalle, London, UK, pp 295- 300

Bhattacharyya HK, Fazili MR, Buchoo BA and Akand AH, 2012. Genital prolapse in crossbred cows: prevalence, clinical picture and management by a modified Bühner's technique using infusion (drip) set tubing as suture material. Veterinarski arhiv, 82(1): 1124

Bhattacharyya HK, Peer FU, Buchoo BA and Ansari MM, 2007. Management of uterine prolapse in cattle. Indian Vet J, 84(7): 744-745

Hasan T, Azizunnesa, Anower P, Paul P and Akter S et al., 2017. Correction and management of vaginal prolapse in a cow by Buhner's technique. Res J Vet Pract, 5(1): 1-4

\section{ACKNOWLEDGMENTS}

The authors would like to acknowledge Dean, FVSc \& AH, SKUAST-J for the facilities provided during the present study.

Henricks DM, Dickey JF, Hill JR and Johnston WE, 2011. Plasma estrogen and progesterone levels after mating, and during late pregnancy and postpartum in cows. J Endocrinol, 90(5): 13361342

Jena B, Pagrut N and Painuli A, 2013. Surgical resection of type II rectal prolapse in a cow. Vet Clinical Sci, 1(1): 19-23

Noakes DE, Perkinson TJ and England GCW, 2009. Post parturient prolapse of the uterus. Arthur's Veterinary Reproduction and Obstetrics, pp 319-323

Patra BK, Nahak AK, Dash SK, Sahu SS and Das SP et al., 2014. Cervico vaginal prolapse in a pregnant cow and its Management- A case report. Int J Livestock Res, 4(5): 55-59

Roberts SJ, 1971. Veterinary Obstetrics and Genital Diseases. 2nd Edn., Edwards Brothers, Inc., Ann Arbor, Michigan, pp 308-313 